блюдению инвариантных для всех стилей и теоретических установок способов как вербального, так и невербального самовыражения.

В современном искусстве сценической речи происходит отказ от жестокого противопоставления собственно языковых и пластических средств выразительности, преобладает синтетическая тенденция. Жест - одна из тайн как ораторского, так и сценического искусства. Жест тесно связан с эмоцией, поскольку любая эмоция может быть выражена жестом. Эмоция предоставляет жесты выразительности. Жест, в свою очередь, помогает выхода эмоции из недр подсознания. Их гармоничное содружество сопровождает языковой дискурс.

Не секрет, что учитель с помощью техники речи, так же, как оратор и актер, может вложить гораздо больше смысла в то, о чем он говорит. Владение голосом является важнейшим средством создания имиджа педагога, хотя в его творческой деятельности преобладает публичная сторона речи. Публичная и сценическая речь имеет такие виды информации: логико-семантическую, эмоционально-экспрессивную и эстетическую. Реализуется эта информация в большей степени из-за технического совершенства языка. Значительно влияют на уровень технической выразительности интонационная содержательность и психологическая наполненность речевого звучания. Разборчивую, норматив- ную и эмоционально - экспрессивную окраску речи создают комплекс выразительных средств, влияющих на художественно-эстетические качества речи.

Для учителя и актера важно осознать, что одной из основных функций языка, как коммуникативной системы, является эмотивная, то есть функция передачи информации об эмоциональном состоянии говорящего. Во время перцепции речевого сообщения интонационные и тембральные параметры языка не только предоставляют информацию слушателю о состоянии говорящего, но и в значительной степени «заражают» его соответствующей эмоцией. Механизм такого воздействия является не выявленным, но, очевидно, он связан с вытеснением тембральных характеристик на периферию сознания. Очевидно, что использование соответствующих свойств языка является одним из основных приемов сценической и педагогической речи.

Современная сценическая речь занимает особое место среди функциональных видов языка, играет определенную роль в обществе и в культуре народа. В условиях интеграции и глобализации общественных процессов сценическая речь в театральных учебных заведениях рассматривается как узкопрофильная дисциплина, направленная на изучение ее только в среде театральной. Однако, речевая деятельность является важнейшей составляющей культуры каждой личности, а особенно - учителя.

\title{
Литература:
}

1. Петрова А. Н. Сценическая речь. М. 2009.

2. Гладков Б. В. О полётности сценического голоса. Теория и практика сценической речи. СПб., 1992.

\section{Причины возникновения и история развития иммерсивного театра}

Попович Петар, студент магистратуры

Санкт-Петербургский государственный институт культуры

В статье изучаются исторические корни и генезис жанра имлерсивного театра начиная с вагнеровской концеепции «универсального произведения искусства», работы П. Керженцева, А. В. Луначарского и А. Арто об активизации зрителя до трудов Ричарда Шехнера, В. Э. Вершковского, А. Д. Силина и Ханс-Тиса Лемана. В статье рассматриваются ключевые этапь развития понятия иммерсивный театр, эго специфика и причинь возникновения.

Ключевые слова: иммерсивный театр, вовлечение зрителя, перформанс, современный зритель, театрализованное представление.

$\prod^{2}$ онятие «Иммерсивный театр», обозначающее конкретное направление в живой практике перформанса, вошло в академическую и артистическую среду примерно в 2004 году, а архивный поиск показывает, что оно вошло в лексикон театральных критиков примерно в 2007 году. В то время понятие использовалось в отношении «иммерсивных постановок в музеях и местах культурно-исторического наследия» $[1$, с.66]. Это были интерактивные события с привлечением артистов, включавшие элементы иммерсивной практики: привлечение посетителей наряду с участием живых исполнителей и применением различных медийных средств поощрялось как часть аутентичного участия в экспозициях. Такие театрализованные события практиковались с целью оживить выставки и площадки. На основе этого можно заключить в своем начальном формате, что иммерсивный театр был ближе к театрализованным представлениям, чем самом театру. Эти театрализованные события можно определить как часть непрерывного 
процесса иммерсивной практики, в ходе которой зрители вовлекаются в происходящее в качестве эксперимента. С 2005 по 2010 год использование данного термина, за неимением лучшего, начинает закреплять указанную практику в качестве жанра. Иллюстрация к этому - использование термина в прессе [2], онлайн-блогах, в интернете, в Твиттере и Фейсбуке, и, в уже более недавнем времени в программировании, постановке маркетинговых задач или задач компании в определенных областях театрального мира.

Для установления причины возникновения иммерсивного театра необходимо ответить на вопрос: в какой момент происходит вовлечение публики в зрелище? Корни иммерсивного театра и вовлечения зрителя лежат в вагнеровской концепции «универсального произведения искусства»Gesamtkunstwerk, в идеи об активизации зрителя, о которой, после Октябрьской революции, писали П. Керженцев, А. В. Луначарский. Эти идеи использовались В. Э. Мейерхольдом, а также в модернистских экспериментах в Тотальном театре под сильным влиянием Мохой-Надь и А. Арто. Сегодняшняя практика расширяет «аксиомы театра окружающей среды», определенные Рихадом Шехнером в 70-х годах [3, с.52], не обращая внимание на работы В. Э. Вершковского и А.Д. Силина, где вовлечение зрителя в театрализованное представление является художественным требованием действия. Тем не менее, термин «иммерсивный», как таковой, нынче применяется к артистическому опыту плоды обсуждений компьютерных технологий и виртуальных сред в 80-е годы. Определенные техники и способности к ощущениям, можно напрямую отследить с периода модернизма (1905-1959), в основном благодаря междисциплинарным взаимосвязям театра, танца, фильма, ви зуального/концептуального искусства и художественной инсталляции - и до текущих изысканий, связанных с интерактивными играми. Практика модернизма эволюционировала от вагнеровской дефиниции Gesamtkunstwerk. С другой стороны, по законам массового представления в Советском Союзе 1920-х годов, зрители должны стать участниками. Рассматривая зрителя в исполнительской роли описывая театрализованные представления П. Керженцев пишет, что «празднество останется мертвым и холодным, если сама толпа не явится действующим лицом его, а будет лишь спокойным театральным зрителем... Празднество не будет празднеством если толпа своим творческим участием не превратит его в таковое» [4, с. 161]. Эксперименты с целью активизации зрителя исследовал В. И. Мейерхольд, использовав прием «подсадки», т. е. размещении актеров среди зрителей или перенос действия в зрительный зал и в фойе. Н. П. Охлопков в своих представлениях боле всех стремился к непосредственному контакту с зрителями. Так, например, в постановке «Железного потока», актеры, которые играли революционеров, бросались со сцены в зал, обнимали и целовали зрителей. В другой постановке в сцене пира, актеры угощали зрителей едой и напитками. Все подобные изыскания становились приемами нового массо- вого, площадного театра. В освещении влияния модернизма и его различных видов эстетики, важно выделить существенность «Театра жесткости» Арто, где он пишет:

«Мы хотим воскресить идею тотального спектакля (spectacle total), взяв у кинематографа, мюзик-холла, циирка и самой жизни все, что испокон веков принадлежало театру... Нельзя отделять ни дух от тела, ни чувства от ума, тем более, когда в результате постоянного переутомления органь чувств нуждаются в резкой встряске, чтобы восстановить свою способность к восприятию. Итак, с одной сторонь, масса и протяженность спектакля, воздействующего на весь человеческий организм целиком, с другой - активная мобилизация объектов, жестов, знаков в их новом качестве» [5, с.175].

Иммерсивный театр можно рассматривать как парадигму этого, поскольку он в значительной мере воплощает данный манифест для театра в блистательной, воспринимаемой чувствами практике. Арто стал первым, потому что его теории вдохновляли театральных экспериментаторов в шестидесятые годы и далее. Теория и практика Арто непосредственно повлияли на практику Ежи Гротовского в Польше, Джулиан Бек и Джудит Мейлина - зачинщиков Живого театра (The Living theatre) в Северной Америке, Ричарда Шехнера и его Перформанс-группы (The Performance Group), Тацуми Хидзиката и Қацуо Оно — coздателей театра Буто в Японии, и Питера Брука в Британии. Все они работали примерно в одно и то же время, иногда сотрудничая, или влияя друг на друга, но неизменно беря за основу принципы Арто. Это произошло благодаря тому факту, что в манифесте было что-то идущее против представлений о том, каким надлежит быть театру. Труды Арто, в частности, наряду с большим списком новаторов периода модернизма, оказали огромное влияние на теорию и практику перформанса, результатом чего стал новаторский подход к сценографии, отношениям между актером и зрителями, и появление высоко физических стилей перформанса. Эксперименты более недавнего времени с иммерсивными технологиями в перформансе развили идеалы Арто и повлияли на обращение художников к интерактивности, с целью усиления сенсуального и образного вовлечения. Большая часть иммерсивного театра, будь то диалог со зрителем в формате «один на один» или масштабная постановка, черпает вдохновение в эстетике «тотальной инсталляции , в которой сценографическая часть опыта предполагает «не только физическое погружение зрителя в трехмерное пространство, но и психологическое вовлечение» [6, с.87]. Эстетика тотальной инсталляции ярко представлена в работах Дримтинкспик (Dreamthinkspeak), Лундаля и Зейтла (Lundahl \& Seitl), Меркуриали (Mercuriali), Нимбл Фиш (Nimble Fish), Панчдранк (Punchdrunk) и, в особенности, УайлдУоркс (WildWorks).

Тем же самым образом как труды Арто влияли на западную театральную практику, труды Н. Евреинова стали основой дальнейших исследований В. Э. Вершковского 
и А. Д. Силина, связанных с театрализаций жизни. Между Евреиновым и Арто не было взаимовлияния, каждый развивал свою теорию самостоятельно, хотя в 1930 -е годы деятельность обоих протекала в Париже. Н. Евреинов создал термин «театрализация жизни», объяснив его как «акт создания новой реальности» $[7$, с. 9]. Создание такой новой реальности внутри настоящей является одной из главных целей иммерсивной практики. Конечно, Арто использовал термин «театрализации жизни», хотя и видел начало театра в различных жизненных проявлениях. «Театрализация жизни», по Арто, это ситуация, в которой жизнь превращается в подлинный театр, где между людьми устанавливаются внелогические связи. Интересно, что художественные программы Евреинова и Арто достаточно близки, прежде всего, в определении значения театра. Картина мира выстраивается у обоих именно через разработку модели театра, а театр в их замысле способен преобразовать мир и реализовать в человеке творческое начало. В то время, когда театральные экспериментаторы шестидесятых и семидесятых годов вдохновлялись и видели новое искусство в работах Арто, в Советском Союзе режиссеры-практики, как Д. Генкин, А.Д. Силин и В. Э. Вершковский, пытались осмыслить теоретические вопросы организации театрализованных действ, исследуя теории Н. Евреинова. Таким образом, «театрализация» рассматривалась как организация праздничного действа по законам театра. Все авторы отмечают, что для театрализации характерен «синтез художественного вымысла и действительности, рождающий новое, неповторимое документально-художественное действие».

Разница между востоком и западом заключалась в том, что запад в центр внимания ставил артефакт, произведение искусства на основе другого искусства, а восток использовал факт, произведение искусства на основе документа. Сутью театрализации, о которой пишут авторы, является «эстетическое осмысление реальных событий, при котором эти события воплощаются в яркой образной форме, содержащей их художественную интерпретацию». В центре их внимания, как на западе был перформанс, нашлось театрализованное представление, которое помимо того, что отражает действительность в художественных образах, активно, пропагандирует политические, общественно-значимые идеи. Весь механизм режиссуры был построен, относительно, на этой уникальной форме, которая объединяет в себе искусство и идеологию. Учитывая, что с 1991 -го года идеологии боле не существовало, механизм режиссуры театрализованных представлений начал обращаться к западным примерам и цифровым технологиям в постоянном поиске нового языка, ориентируясь больше на телезрителя, чем зрителя на площади. Таким образом, обновление режиссерского языка театрализованных представлений не произошло, а появился новый зритель, осведомлённый о современном зрелищно-игровом мире и которому пассивное наблюдение, не является достаточным, чтобы получить удовольствие.
Вовлечение зрителей не представляет что-то новое в театральной практике, а понятие «активизации зрителя» можно отследить через почти весь ХХ век, но в современном смысле, зрителя стоит рассматривать как участника самого перформанса, влияющего на его развитие. Одним из концептуальных пунктов происхождения перформанса, в традиции изящного искусства, является присутствие «наблюдающего за действом в ограниченном по времени акте его создания и приёма, и отношение художника к этому акту и наблюдающему» $[8$, с. 94]. Эта работа, с формальной точки зрения, носит характер эксперимента, так что взаимопроникновение ролей зрителя/участника вполне ожидаемо. Явная связь между художественными акциями и театром иногда очевидна, как в случае сотрудничества Перформанс-Группы с Алленом Капроу на раннем этапе, а также в период существования «театра окружающей среды» в ходе инсталляции «HG» Роберта Уилсона и Ганса-Питера Куна (1995). Участие зрителей в театре можно отследить до шестидесятых годов, в работах Перформансгруппы и Ричарда Шекнера, а также и раннего использования «одновременной драматургии» Аугустуа Боала. Такое участие имело место в живых арт-перформансах и хэппенингах Қапроу. Такой подход, конечно, не нов, но, похоже, он еще частично в ходу - особенно явно это заметно в лондонских экспериментальных театрах последних десятилетий. Самые успешные постановки иммересивного театра, в периоде с 2000 до 2010 года, которые произошли только в Лондоне: «Вилья Вилья» (1999/2000) и «Фуэрцабрита» от Де Ля Гарда; «Танцуй, медведь, танцуй» (2003) и «Амато Сальтоне» в постановке театра Шант (2006); «Фауст» $(2005)$ и «Маска Красной Смерти» (2007) в постановке театра Панчдранк; «Публика и Параактивный» (2009-2010) Тима Кроуча, «Отель «Медея» (2009-12) Зекора Ура.

Сам перформанс является достаточно новым элементом театрализованного представления для русских театральных практиков несмотря на то, что перформативное искусство в России существовало с 1970-х годов. Перформанс воплощает в себе совершенно особые принципы, основываясь на спонтанности, абсурдности, в то же время, выполняет эстетическую функцию, тем самым раскрепощая зрительскую аудиторию. Появление нового элемента в театрализованных представлениях требует от авторов и режиссеров нового типа драматургического мышления, умения создавать атмосферу поверх основного действия, организовать взаимодействие исполнителей и аудитории. Кроме перформанса, иммерсивный театр играет с формами инсталляционного искусства наряду со слиянием зрителей и актеров и взаимодействием с пространством и в пространстве. Обычно это сопровождается неким видом взаимодействия артиста и человека из публики, разработанным для того, чтобы подчеркнуть чувственное вовлечение и психологическую сосредоточенность в рамках перформанса. Использование игровой площадки в иммерсивном театре, это попытка избавить его от текста современной драмы. Место 
используется для создания эфемерных пейзажей, занимающих место текста. О подобном писал и А. Д. Силин: «Массовое зрелище должно быть действенно-динамичным, зрелищным, эмоциональным и образным. Ему категорически противопоказаны статично декламационные, так называемые «разговорные» эпизоды и сцены» [9, с. 92]. В этом смысле иммерсия отображает средство режиссуры, подходящее современному зрителю. Действительно, аспекты иммерсии, вторящие видеоиграм и играм с виртуальной реальностью в качестве полностью придуманных конструкций, происходящих все более иммерсивно, бросают вызов любому определению, якобы обсуждаемой здесь театральной практики. Влиятельная работа Ганса-Тис Леманна «Пост драматический театр» (2006) выражает некоторые проблемы, вызванные с классификацией иммерсии:

«Перед лицом давления, оказываемого объединенными силами скорости и поверхности, театральный дискурс освобождается от литературного дискурса, но в то же время сближается с ним в рамках его общей внутрикультурной функции. Как для театра, так и для литературь, текстурь, особенно зависимые от выброса активной энергии воображения, энергии, которая слабеет в циивилизации первоочередного пассивного потребления образов и данных. Театр означает коллективно потраченное и использованное время жизни в коллективно вдыхаемом воздухе того пространства, в котором происходит исполнение ролей и наблюдение. Этот кардинально измененный метод использования театрального знака указывает на то, ито имеет смысл описать значимый сектор нового театра как «пост драматический» [10, с.16].

Анализ культурного момента, выполненный Леманном, обновляет границы места во время погружения. «Скорость и поверхность сдвинули цели театра и литературы, когда «пассивное потребление образов» превратилось в массовое явление. Спектакль, о котором будут еще писать, «Тут она упала» переносит участников в неизвестную точку эпохи Льюиса Кэррола, в XIX столетие, воспроизводит сигнальное манипулирование пространством и временем, подробно расписанное Леманном. Начав свой путь в комнате для ожидания, до краев наполненной книгами, медицинским архивом и гигантским столом, участники продолжают испытывать переживание, проходя через множество комнат и переживая множество контактов индивидуально, для каждого участника. Ни одно из двух путешествий не похоже на другое, и, как результат, ни один из двух людей не вступает в одинаковый контакт, не ведет одинаковых разговоров, и даже няни и доктора, ведущие его по проходам внутри здания, всегда разные. Соответственно, ни один нарратив данного пространства не будет полным. Никакое описание характера персонажа не будет психологически глубоким, даже выполненное Льюисом Кэрроллом, т. к. участник может только направлять свой путь по пространству и времени, в глубину душевного склада персонажей. Когда добавим к этому изменения пространства, включающие прихотливые образы и персонажи из книг Кэррола, то и время, и место сами по себе станут тягучими, интерпретируемыми и рефлексивными. Такое театрализованное действо, как правило, у глаз зрителя одноразово и существует как бы в единственном экземпляре. Это один из важных элементов, приближающий постановки иммерсивной практики больше к театрализованным представлениям, чем к традиционном театру. Қаждый зритель, выбирая свой путь через постановку создаёт для себя уникальное и неповторяемое представление. Эта «эксклюзивность» во многом помогала и театральным продюсерам финансировать более комплексные представления, так как зритель современного мира готов заплатить за уникальный опыт. Это помогло развитию иммерсивной практики, но также позволило различным более или менее интерактивным спектаклям использовать прилагательное «иммерсивный».

Сегодня существует растущая тенденция среди артистов театра и продюсеров, навесить на свои представления название «иммерсивный», но не всякое вовлечение зрителей можно причислить к категории иммерсивного, хотя и сейчас определение еще довольно смутное. Установка на пребывание внутри действа, навлеченная идеей иммерсивности, резонирует с опытом открытия в себе возможности совершать поступки в рамках происходящего, под влиянием своего иного «я», обновившегося в результате такого переживания - это особые черты участия зрителей. Тем не менее, там, где Леманн заявляет, что данный тип театра, «скорости и поверхности, описывает пассивный набор импульсов, устраивающий засаду для воображения», можем утвердить, что он призывает участников к более активным действиям в границах данного места.

Литература дает начало, середину и конец, с текстовыми знаками, у которых есть широкие, абстрактные знаки. Разрывание текста по пространствам ограничивает языковые абстракции. В таких обстоятельствах индивидуумы связывают отдельные значения с объектами, персонами и местом, как таковым. А раз так, иммерсивный театр - это пост драматический театр, расшатывающий примат драмы и литературы. Леманн продолжает: «B пост драматиче ских формах театра сценический текст (если текст сценический) - это просто часть общей компози цуии, объединяющей жесты, музыку, визуальный ряд и т.д. Разрыв между дискурсом текста и дискурсом театра может стать путем к открыто выраженному противоречию, и даже кне связанности (поняmuй)» $[10$, с.57]. Иммерсивная практика допускает возможность такой не связанности. Тем не менее, постановки такие, как «Тут она упала» призывают участников уступить контроль над интерпретацией в обмен на сенсуальные, интуитивные и манипуляторные импульсы. Хотя они могут быть искушающими, эти перформансы вовлекают зрителей в качестве актеров в места со строгими границами и событиями, выдающие себя за уникальные, индивидуальные и интимные разовые опыты. 
Такой подход к современному зрителю резко отличается от практики современных театрализованных представлений, которые приобретают черты шоу-программы, где основной смысловой единицей для зрителя становится знакомая концепция подачи. Так, задача режиссера превращается в режиссуру одного номера, относительно которого остальные элементы строятся как сценические украшения. В иммерсивных форматах упор делается на приготовление к шоу, когда режиссеры стремятся к проработке откликов участников на разворачиваемые действия в спектакле. Вероятно, наиболее часто цитируется и принимается определение иммерсии в отношении к современному зрителю автора Дженет Муррей: «Mы пытаемся испытать те же чувства от психологически иммерсивного переживания, что мь испытываем, погружаясь в океан или в бассейн. Ощущение, что тебя окружает совершенно другая реальность, отличающаяся так же, как вода от воздуха, которая отвлекает на себя все наше внимание, весь наш аппарат ощущений. В среде участия, иммерсия - это обучение плаванию, освоение вещей, которые делает доступными новая среда» [11, с.98]. Это идея не только погружения в воду, о котором уже упоминалось, но и процесса обучения плаванию, предполагает активную и осмысленную форму иммерсии, большую, чем насыщение ощущениями.

Рассмотрение темы происхождения иммерсивного театра в опубликованных теоретических трудах представляет сложную задачу, т. к. многообразная природа иммерсивной практики еще только развивается, и научных исследований представлено еще не так много Основные источники для такого анализа представляют работы трех теоретиков Гэрета Уайта, Джозефины Мэйхон и Эдама Элстона.

Характерные черты иммерсивного театра обусловлены синтезом художественных, идеологических и эстетических традиций. Гэрет Уайт, прикладной практик театра, утверждает, что: «исторические корни иммерсивного театра можно отследить до политического искусства участия 60-х годов, но форма эволюционировала явно, из политической ориентации, оставляя больше места для эстетических и тематических инноваций» [12, с. 15]. Таким образом, Уайт предлагает набор качеств и характеристик иммерсивного театра, предполагая его различия в форме, содержании и стиле: «имея цуелью пересмотр взаимоотношений между публикой и исполнителем через организацию, структуру, степень сближения» [12 c. 16]. Уайт также приводит выдержки из теорий эмансипированного пассивного зрителя, выделенные Жаком Рэнсьером, и теории акта отношений, описанные Буррио, в которых иммерсивный театр описан как неразрывно связанный с вовлеченным пассивным наблюдением.

Путем расширения и продления диалога с Уайтом, Джозефина Мэйхон, ведущий исследователь практики иммерсивного театра, предлагает его детальные описания, определяя «иммерсивность, иммерсию и иммерсивити». В своих исследованиях Мэйхон приходит к понятию«всеохват- ного художественного переживания» и привлекает историю технологий, особенно игровых технологий, чтобы обозначить включение «иммерсивного» в дискурсы перформанса. Қак и Уайт, Мэйхон также привлекает теоретиков искусства отношений, включая Буррио, для при влечения идей интерактивности и расширенного участия в спектакле. Она утверждает, «что иммерсивный театр определен, по меньшей мере, частично, «эволюцией через вовлечение», когда публика становится больше, чем просто зрителями, становясь активньми участниками представления - своего рода публика-плюс. В этой парадигме, публика-плюс, люди, посещающие представления иммерсивного театра, являются, прежде всего, зрителями, а уже потом компаньонами. Акт взаимодействия с актерами дает в результате новую форму пассивного созерцания, разрешенную в границах театральных и перформативных переживаний»[1 с.112]. В суждениях и Уайт, и Мэйхон выделяется понятие «эволюционирующего зрителя», все в большей степени свободного от традиционных представлений о поведении публики (сидеть тихо, пассивно вникать в повествование и т.д.), и активного участника театрального действа. В определении иммерсивного театра, через указанные идеи освобожденного пассивного наблюдения и эволюции через вовлечение, Мэхон и Уайт останавливаются, не в силах прояснить, какие особые условия приводят к такой эволюции публики. Эдам Элстон поднимает эти вопросы в своем эссе, рассматривая иммерсивное шоу в современном контексте неолиберализма. Он рассматривает аспект участия иммерсивного переживания зрителя как «предпринимательский» $[13$, с.52] в том плане, что оно превозносит неолиберальные принципы, такие, как риск, действие и личную ответственность. Такое воплощение неолиберальной экономической практики, выступающей как ключевой фактор влияния в иммерсивном театре, подтверждает предположения Уайта и Мэйхон о принципах эволюции. Выдвигая мысль, что театральная публика, погруженная теперь в «гипер - индивидуалистический, замешанный на технологии, неолиберальный контекст западного постмодернизма требует роль, выходящую за рамки пассивного участия в спектакле, зачастую центральную в большинстве театральных постановок» [12, с.71], Элстон предлагает другое важное контекстуализирующее мнение относительно того, почему иммерсивный театр нашёл столько энтузиастов среди зрителей. В действительности, «иммерсивный театр явился прямым ответом на современный культурный, политический и экономический дух времени, творя искусство, которое и вовлекает, и развлекает публику посредством все более обновляемого мира живого перформанса» [13, с.44].

В совокупности эти идеи, включая связь с политическим «искусством участия», связь с интерактивными технологиями и играми и возвышение роли неолиберальных ценностей представляют собой рамки принуждения, че рез которые предполагается рассматривать иммерсивный опыт и его взаимоотношения с театральными инновациями. 
Помимо всего, эти суждения предполагают, что иммерсивный театр создается для переопределения и переосмысления взаимоотношений с публикой, посредством экспериментов с вовлечением пассивных зрителей.

Сегодня «иммерсивный» используется для описания направления в современной практике перформанса, в котором акцентируется внутреннее чувства зрителей и их опыт вовлечения в действо, в сочетании с всепоглощающим, воспринимаемым чувствами, стилем эстетики постановки. По этой причине понятие «иммерсивный» ныне используют, и нередко не по делу, в отношении всех видов театра, чье действие разворачивается в нетрадиционных местах и/ или подразумевает вовлечение публики. Понятие можно использовать при описании студийных работ с привлечением к участию зрителей до того, как они займут места в зрительном зале. Соответственно, существует опасность, что термин закрепится в отношении любой постановки, происходящей вне традиционного театра со статичными зрителями и до определенной степени, привлекающей междисциплинарную практику - это, как минимум, вводит в заблуждение. Такая неопределенность в применении понятия указывает на то, насколько важно было определить, к чему конкретно относится данное понятие, и до какой степени.

Литература:

1. Machon, J. Immersive Theatres: Intimacy and Immediacy in Contemporary Performance / J. Machon - Palgrave Macmillan UK, 2013. - 348 p.

2. Trueman, M. Immersive theatre: take us to the edge, but don't throw us in. URL: https://www.theguardian.com/ stage/theatreblog/2010/apr/07/immersive-theatre-terrifying-experience (Дата обращения: 30.03.2019).

3. Schechner, R. The Drama Review: TDR / R. Schechner. - Architecture/Environment. - 1968. — Vol. 12, № 3. P. $41-64$.

4. Керженцев П. М. Творческий театр / П. М. Керженцев. - М.; Пг.: Госиздат, 1923. - 233 с.

5. Арто, А. «Театр и его Двойник. Манифесты, драматургия, лекции, философия театра». СПб: Симпозиум, 2000. $448 \mathrm{c}$.

6. Participation (Documents of Contemporary Art) / Editor: C. Bishop - Cambridge, Massachusetts, The MIT Press, 2006. - 240p. (Перевод Чистяков Т. Э.).

7. Евреинов Н. Н. Демон театральности / Сост., общ. ред. и комм. А. Ю. Зубкова и В. И. Максимова. - М.; СПб.: Летний сад, 2002. - 535 с.

8. Carlson, M. Performance: A Critical Introduction / M. Carlson. — London and New York: Routledge, 1996. — 288p. (Перевод Чистяков Т.Э.)

9. Силин А. Д. Площади - наши палитры / А.Д. Силин. - М.: Советская Россия, 1982. - 184 с.;

10. Lehmann, H. - T. Postdramatic Theatre (1st Edition) / H. - T. Lehman - Routledge, 2006. - P. 46.

11. Murray, J. H. Hamlet on the Holodeck: The Future of Narrative in Cyberspace / J.H. Murray - Cambridge, MA: MIT Press, 2017. - 440p.

12. White G. Audience Participation in Theatre: Aesthetics of the Invitation 2013th Edition / G. White - Palgrave Macmillan UK, 2013. - 236p.

13. Alston A. Beyond Immersive Theatre: Aesthetics, Politics and Productive Participation 1st ed. 2016 Edition/ A. Alston - Palgrave Macmillan UK, 2016. - 256 p.

\section{Virtual museums as a PR-tool}

Tanashova Aidana Nurlankyzy, master student

Kazakh National University named after Al-Farabi (Almaty)

This article discusses the importance of developing and improving the museum marketing in the field of virtual museums and identified basic tools that help museums promote the brand.

Keywords: virtual museums, real museums, marketing, promoting tools.

$\mathrm{F}$ rank Jeffkins, a well-known researcher of public relations technologies, notes: "Public relations consists of all forms of systematically implemented communication, external and internal, between the organization and its public in order to achieve between them mutual understanding" [1].
A virtual museum is often called the site of a real museum. Thus, it is possible to single out two varieties of virtual museums. The first includes sites that reflect in the virtual space of the collection and the exposition of real existing state, municipal and private museums. These are sites created on the 